\title{
Real-world direct-acting antiviral treatment in kidney transplant and hemodialysis patients: the EpiTer-2 multicenter observational study
}

\author{
Olga Troninaa, Magdalena Durlika, Iwona Orłowskab ${ }^{b}$, Beata Lorencc, Tadeusz W. Łapińskid, \\ Aleksander Garlicki ${ }^{\text {, }}$ Dorota Dybowskaf, Dorota Zarębska-Michaluk ${ }^{\mathrm{g}}$, Magdalena Tudrujek-Zdunek ${ }^{\text {h }}$, \\ Jolanta Citkoi, Ewa Janczewska', Marcin Kaczmarczykk', Jerzy Jaroszewicz', Rafał Krygierm, \\ Jakub Klapaczyński ${ }^{n}$, Beata Dobrackaº, Jolanta Białkowska-Warzechap ${ }^{p}$, Anna Piekarskaq, \\ Krzysztof Simon ${ }^{\text {b }}$, Waldemar Halota ${ }^{f}$, Małgorzata Pawłowskaf, Krzysztof Tomasiewicz ${ }^{\text {h }}$, Robert Flisiak ${ }^{\text {d }}$
}

Medical University of Warsaw, Warsaw; Wrocław Medical University, Wrocław; Medical University of Gdańsk, Gdańsk; Medical University of Białystok; Jagiellonian University Collegium Medicum, Kraków; Collegium Medicum Bydgoszcz, Nicolaus Copernicus University, Toruń; Voivodship Hospital and Jan Kochanowski University, Kielce; Medical University of Lublin; Regional Hospital, Olsztyn, Poland; ID Clinic, Mysłowice; Specialist Hospital in Chorzów, Medical University of Silesia, Katowice, Poland; Medical University of Silesia in Katowice, Bytom; Outpatient Clinic NZOZ "Gemini", Żychlin; Central Clinical Hospital of the Ministry of Internal Affairs and Administration, Warsaw; MED-FIX Medical Center, Wrocław; Medical University of Łódź, Poland

\section{Abstract}

Correspondence to: Olga Tronina MD, PhD, Department of Transplantation Medicine, Nephrology, and Internal Diseases, Medical University of Warsaw, Nowogrodzka 59; 02-006 Warsaw, Poland, e-mail: olgatronina@wp.pl

Received 13 September 2020; accepted 22 October 2020; published online 5 February 2021

DOI: https://doi.org/10.20524/aog.2021.0595
Background Patients who undergo hemodialysis (HD) or kidney transplantation (KTx) previously had limited possibilities for treatment of hepatitis C virus (HCV) infection. Directacting antivirals (DAA) give these patients a chance of virus eradication and safe transplantation. The aim of this study was to evaluate the effectiveness and safety of DAA in KTx and HD patients in real-world settings.

Methods Sustained virologic response (SVR) and treatment safety were analyzed in KTx and HD patients from the EpiTer-2 database, which included HCV-infected subjects treated with DAA between 2015 and 2019. Additionally, for KTx patients, changes in creatinine concentration, estimated glomerular filtration rate (eGFR), proteinuria within a year after treatment, and changes in the need for calcineurin inhibitors were assessed.

Results Among 10,152 patients from the EpiTer-2 database 148 were selected, 85 after KTx and 63 undergoing HD. The most common genotype, $1 \mathrm{~b}$ HCV, was found in $73 \%$ and $86 \%$ of patients, respectively. Cirrhosis was noted in $10 \%$ and $19 \%$, respectively. The most common DAA regimen after KTx was sofosbuvir/ledipasvir (54\%), whereas in HD patients it was ombitasvir/paritaprevir/ ritonavir $+/$ - dasabuvir (56\%). All patients with available follow-up results achieved SVR. No deaths, kidney loss or acute rejection episodes were noted. The most common adverse effects in both groups were anemia and weakness. One year after treatment, creatinine concentration, eGFR and proteinuria remained stable in the majority of patients.

Conclusion DAA treatment of HCV infection demonstrated high effectiveness and safety in hemodialyzed patients and patients who had undergone KTx in this real-world study.

Keywords Antiviral treatment, chronic hepatitis Cinfection, direct-acting antivirals, hemodialysis, kidney transplantation

Ann Gastroenterol 2021; 35 (1): 1-9

\section{Introduction}

The significant progress seen over the recent years in treating hepatitis $\mathrm{C}$ virus (HCV) infection, due to the introduction of direct-acting antivirals (DAA), has become an opportunity to eradicate the virus among the most susceptible groups of patients, i.e., those suffering from cirrhosis, post-transplant or 
hemodialysis patients. According to data from the World Health Organization, the issue of hepatitis C involves 71 million people, and each year approximately 400,000 die from cirrhosis and/ or hepatocellular carcinoma [1]. Extrahepatic manifestations accompanying a chronic HCV infection, including diabetes, cardiovascular disorders or glomerulopathy, increase the prevalence and mortality of infected patients [2-5].

Medical procedures with tissue breakdown, sanitary negligence and the necessity of blood transfusion in resistant anemia are the main reasons why HCV infections are more common in patients with chronic kidney disease [6,7]. According to data presented in the KDIGO 2018 report, the frequency of $\mathrm{HCV}$ infection in hemodialysis patients is from 3.8-31.1\%, depending on the region [7]. HCV-infected kidney

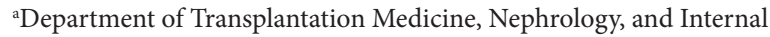
Diseases, Medical University of Warsaw, Warsaw (Olga Tronina,

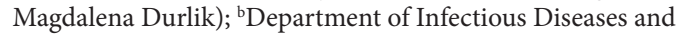
Hepatology, Wrocław Medical University, Wrocław (Iwona Orłowska, Krzysztof Simon); 'Pomeranian Center of Infectious Diseases, Department of Infectious Diseases, Medical University of Gdańsk, Gdańsk (Beata Lorenc); ${ }^{\mathrm{d} D e p a r t m e n t ~ o f ~ I n f e c t i o u s ~ D i s e a s e s ~ a n d ~}$ Hepatology, Medical University of Białystok, Białystok (Tadeusz W. Łapiński, Robert Flisiak); ${ }^{\mathrm{e} D e p a r t m e n t ~ o f ~ I n f e c t i o u s ~ a n d ~ T r o p i c a l ~}$ Diseases, Jagiellonian University Collegium Medicum, Kraków

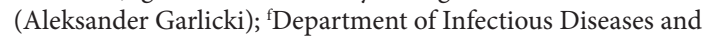
Hepatology, Faculty of Medicine, Collegium Medicum Bydgoszcz, Nicolaus Copernicus University, Toruń (Dorota Dybowska, Waldemar Halota, Małgorzata Pawłowska); ${ }^{8}$ Department of Infectious Diseases, Voivodship Hospital and Jan Kochanowski University, Kielce (Dorota Zarębska-Michaluk); ${ }^{\mathrm{D}}$ Department of Infectious Diseases and Hepatology, Medical University of Lublin, Lublin (Magdalena Tudrujek-Zdunek, Krzysztof Tomasiewicz); ${ }^{i}$ Medical Practice of Infections, Regional Hospital, Olsztyn, Poland (Jolanta Citko); ${ }^{j}$ Hepatology Outpatient Clinic, ID Clinic, Mysłowice, Poland (Ewa Janczewska); ${ }^{k}$ Clinical Department of Infectious Diseases, Specialist Hospital in Chorzów, Medical University of Silesia, Katowice, Poland (Marcin Kaczmarczyk); 'Department of Infectious Diseases, Medical University of Silesia in Katowice, Bytom (Jerzy Jaroszewicz); ${ }^{\mathrm{m}}$ Infectious Diseases and Hepatology Outpatient Clinic NZOZ

"Gemini", Żychlin (Rafał Krygier); " Department of Internal Medicine and Hepatology, Central Clinical Hospital of the Ministry of Internal Affairs and Administration, Warsaw (Jakub Klapaczyński); ${ }^{\circ}$ MED-FIX Medical Center, Wrocław (Beata Dobracka); ${ }^{\mathrm{D}}$ Department of Infectious and Liver Diseases, Medical University of Łódź (Jolanta BiałkowskaWarzecha); ${ }^{9}$ Department of Infectious Diseases and Hepatology, Medical University of Łódź (Anna Piekarska), Poland

Conflict of interest: Dorota Zarębska-Michaluk: Sponsored Lectures: AbbVie, Gilead, Merck

Jerzy Jaroszewicz: Sponsored lectures: AbbVie, Bristol-Myers Squib, DiaSorin, Gilead, Grifols, Roche, Woerwag, MSD Sharp\&Dohme/ Merck; Member of the scientific advisory boards of AbbVie, BristolMyers Squib, Gilead Sciences, MSD Sharp \& Dohme/ Merck and Roche Krzysztof Simon: Consultancy: AbbVie, Abbott, Gilead, MSD, GSK, Janssen, AlfaSigma, Baxter, Promed; Research Funding: Bayer, Gilead, EISAI, AbbVie, Tobira, Intercept, MSD, Janssen, Takeda, Actelion, GSK, Pfizer, BeiGene, Allergan, Summit (Oxford)

Małgorzata Pawłowska: Consultancy: AbbVie, Gilead, Merck, Roche; Sponsored Lectures: AbbVie, Gilead, Merck

Krzysztof Tomasiewicz: Consultancy: AbbVie, Alfa Wasserman, BMS, Gilead, Janssen, Merck, Roche; Research funding: AbbVie, BMS, Gilead, Janssen, Merck, Roche

Robert Flisiak: Consultancy and Research funding: AbbVie, Gilead, Janssen, Merck, Roche transplant $(\mathrm{KTx})$ recipients have worse patient and allograft survival after transplantation compared with uninfected KTx recipients. This happens because in dialysis patients the $\mathrm{HCV}$ infection is associated with greater all-cause morbidity and mortality. The reduced survival is not only related to the decompensated cirrhosis and hepatocellular carcinoma; in these patients $\mathrm{HCV}$ infection is associated with posttransplant proteinuria, episodes of rejection, increased risk of diabetes, cardiovascular diseases, malignancies and allograft loss [8,9].

KTx is the best treatment option for patients with kidney failure. The eradication of the virus before transplant became possible with the introduction of DAA, which not only guarantee a near $100 \%$ virologic response, but have also been confirmed as safe, regardless of the stage of liver fibrosis, previous treatment failures or the stage of chronic kidney disease [10].

Early identification of chronic HCV infection, before the development of cirrhosis and its complications, raises the chances of an effective antiviral treatment. It also prevents the necessity of a risky decision regarding simultaneous kidney and liver transplantation. Moreover, it can affect the survival time of the kidney graft and prevents potential drug-drug interactions [11-15]. DAA therapies are the beginning of a new chapter in obtaining organs from HCV positive donors, which can significantly shorten the transplant waiting time [16-18]. The aim of this study was to assess the effectiveness and safety of DAA treatment in HCV patients who have undergone KTx or hemodialysis in real-world settings. Observations after KTx also included changes in kidney function measured by creatinine concentration, estimated glomerular filtration rate (eGFR), the Modification of Diet in Renal Disease (MDRD) equation, and proteinuria (protein-creatinine ratio) 1 year after the end of the antiviral treatment.

\section{Patients and methods}

\section{Study design}

EpiTer-2 is an investigator-initiated study, supported by the Polish Association of Epidemiologists and Infectiologists, which involved 22 Polish centers involved in the diagnosis and treatment of $\mathrm{HCV}$-infected patients. The database includes 10,152 patients treated for HCV infection in Poland between 2015 and 2019, as was described previously [19]. Data for all patients treated in a therapeutic program reimbursed by the Polish National Health Fund (NFZ) were collected retrospectively with a web-based questionnaire. The regimen was selected from available therapeutic options, based on the physician's judgment, and was administered according to the protocol of the NFZ therapeutic program, product characteristics, and recommendations of the Polish Group of Experts for HCV [20,21]. The current study included patients who had undergone KTx and hemodialyzed patients selected from the main EpiTer-2 database, regardless of the degree of kidney failure measured by eGFR.

The immunosuppressive treatment was modified only when significant drug-drug interactions were expected, such 
as between cyclosporine (CSA) and elbasvir/grazoprevir or glecaprevir/pibrentasvir. In these cases, cyclosporin was switched to tacrolimus (TAC). The decision regarding the date of DAA treatment in relation to the transplant date was made by the attending physician.

\section{Patients}

Of the 10152 patients from the EpiTer-2 database, 148 adults were included in the current study, 85 after KTx and 63 hemodialyzed, treated for chronic HCV infection between July 2015 and July 2019 in 17 hepatologic centers in Poland. Patients were followed for 1 year after the end of treatment (EOT) regarding kidney function after the transplantation. The studied patients, with HCV infection diagnosed for at least 6 months before the beginning of treatment, were infected with genotype (GT) 1-6 and in all stages of liver fibrosis. The stage of liver fibrosis was estimated based on transient elastography and/or liver biopsy (METAVIR). Patients were either treatment naïve or had a history of treatment failure, which included treatment discontinuation due to safety concerns, viremic relapse after treatment termination, nonresponse to treatment or treatment discontinuation due to patient decision or reasons unknown.

All patients receiving immunosuppressive treatment had to have stable calcineurin inhibitor concentrations, which in reality meant a minimum 3 months of observation after transplantation. The treatment duration was from 8-24 weeks. According to the guidelines, after the start of treatment, consecutive visits were scheduled every 4 weeks and 12 weeks after EOT. Medication was administered according to the medical product guidelines. The initial dosage of ribavirin was set by the attending physician, individually for each patient. Any decision on ribavirin dosage modification during DAA treatment was based on clinical or laboratory adverse events.

\section{Assessment of treatment effectiveness and safety}

Effectiveness was evaluated based on the rate of EOT response and sustained virologic response (SVR12), defined as undetectability of HCV RNA in blood 12 weeks after treatment termination. SVR was presented either as intent-totreat (ITT) analysis or after exclusion of patients lost to follow up as a modified ITT (mITT). HCV RNA detection level was $<18 \mathrm{IU} / \mathrm{mL}$, but varied across study centers depending on the assay used $(<15 \mathrm{IU} / \mathrm{mL}$ in $88.0 \%$ of patients). Plasma $\mathrm{HCV}$ RNA concentrations were measured using quantitative polymerase chain reaction assays: COBAS TaqMan HCV v2.0 (Roche Molecular Diagnostics, Pleasanton, CA, USA), COBAS AmpliPrep HCV (Roche Molecular Diagnostics, Pleasanton, CA, USA) and the m2000 Real-Time System (Abbott Molecular, Des Plaines, IL, USA). Safety outcomes, such as adverse events and laboratory abnormalities, were followed during the treatment and 12-week follow-up period. Safety data analysis also included the possible effect of DAA on the function of a transplanted kidney (measured by the creatinine concentration and eGFR, as well as proteinuria), assessment of the risk of acute rejection of the transplanted kidney and interaction with immunosuppressive medications.

\section{Statistical analysis}

Data are presented as means + standard deviations or $\mathrm{n}$ (\%) with respective ranges. P-values of $<0.05$ were considered to be statistically significant. Additionally, calculations were performed using the NVIDIA Jetson TX1 platform and the Python/R language. Consecutive results analysis, their interpretation and export to spreadsheets were conducted using a scientific distribution of Anaconda. The indicated statistical features had their goodness of distribution verified by Cramer von Mises, Lilliefors and Shapiro-Wilk tests and parametric or non-parametric tests were selected for related groups.

\section{Ethics}

Patients were treated with registered medication and anonymized data were collected retrospectively; therefore, informed consent was not required.

\section{Results}

Of the patients who had undergone KTx $51 \%$ were women, and the average age was 50 (range 27-74) years. As shown in Table 1, the most common GT in this group, found in $73 \%$ of patients, was GT1b, followed by GT4 (19\%).

It is worth noting the low level of liver fibrosis (F0-F1) observed in $67 \%$ of patients. Cirrhosis was identified in $11 \%$ of cases. In 2 patients $(2.4 \%)$ an episode of liver decompensation was noted. There were no patients diagnosed with hepatocellular carcinoma. The majority (91\%) of patients were HCV treatment naïve, while the remaining 8 (9.4\%) had failed previous treatment with pegylated interferon alfa. None of the patients was previously administered a DAA regimen. The average time since KTx was 151 months, with the earliest being 3 months after transplantation, which allowed a stable creatinine and calcineurin inhibitor concentration to be obtained. Regarding the current DAA regimen, the majority of patients (73\%) received a 12-week antiviral schema (Table 1). More than half the patients (60\%) were administered a sofosbuvir-based regimen, and $16.5 \%$ of patients were administered ombitasvir/paritaprevir/ritonavir +/- dasabuvir (OPrD). More than half the patients (52\%) received ribavirin in addition to the basic regimen. Apart from 1 patient, who discontinued antiviral treatment after 7 weeks because of adverse events, the remaining patients completed therapy according to schedule. Among 69 patients with detailed data, $25 \%$ had significant transplanted kidney failure with eGFR $<30 \mathrm{~mL} / \mathrm{min} / 1.73 \mathrm{~m}^{2}$, which additionally explained the diversity 
Table 1 Baseline demographics and disease characteristics

\begin{tabular}{|c|c|c|}
\hline \multirow[t]{2}{*}{ Parameter } & \multicolumn{2}{|c|}{ Studied population $n=148$} \\
\hline & Ktx $n=85$ & $\mathrm{HD} n=63$ \\
\hline Females/males, n (\%) & $43 / 42(50.6 \% / 49.4 \%)$ & $25 / 38(39.7 \% / 60.3 \%)$ \\
\hline Age (years), mean $\pm S D$; min- $\max$ & $50.0(11.3) ; 27-74$ & $51(13) ; 25-77$ \\
\hline $\begin{array}{l}\text { HCV genotype, n (\%) } \\
\text { 1a } \\
1 \mathrm{~b} \\
3 \\
4\end{array}$ & $\begin{array}{c}2(2.4 \%) \\
62(72.9 \%) \\
5(5.9 \%) \\
16(18.8 \%)\end{array}$ & $\begin{array}{c}3(4.8 \%) \\
54(85.7 \%) \\
0 \\
6(9.5 \%)\end{array}$ \\
\hline $\begin{array}{l}\text { Fibrosis, } \mathrm{n}(\%) \\
\text { F0 } \\
\text { F1 } \\
\text { F2 } \\
\text { F3 } \\
\text { F4 }\end{array}$ & $\begin{array}{l}8(9.4 \%) \\
49(57.6 \%) \\
10(11.8 \%) \\
9(10.6 \%) \\
9(10.6 \%)\end{array}$ & $\begin{array}{c}1(1.6 \%) \\
22(34.9 \%) \\
14(22.2 \%) \\
12(19.1) \\
14(22.2)\end{array}$ \\
\hline Liver decompensation & $2(2.4 \%)$ & 0 \\
\hline Hepatocellular carcinoma & 0 & 0 \\
\hline MELD, mean $\pm S D$; min-max & $11.8(5.1) ; 6-22$ & $20(3) ; 9-32$ \\
\hline HCV RNA, IU/mL & $\begin{array}{c}3663717.8(5597108.7) \\
350.0-38100000.0\end{array}$ & $\begin{array}{c}2449540.7(538782.6) ; \\
350.0-35000000.0\end{array}$ \\
\hline $\begin{array}{l}\text { Current regimen (weeks) n (\%) } \\
\text { OBV/PTV/r+ DSV (8) } \\
\text { OBV/PTV/r+ DSV (12) } \\
\text { OBV/PTV/r+ DSV+RBV (12) } \\
\text { OBV/PTV/r+ DSV+RBV (24) } \\
\text { OBV/PTV/r+ RBV (12) } \\
\text { OBV/PTV/r+ RBV (24) } \\
\text { LDV/SOF (8) } \\
\text { LDV/SOF (12) } \\
\text { LDV/SOF (24) } \\
\text { LDV/SOF +RBV (12) } \\
\text { LDV/SOF+RBV (24) } \\
\text { SOF + RBV (12) } \\
\text { SOF + RBV (24) } \\
\text { GZR/EBR (12) } \\
\text { GZR/EBR+RBV (16) } \\
\text { ASV+DCV (24) } \\
\text { GLE/PIB (8) }\end{array}$ & $\begin{array}{c}0 \\
6(7 \%) \\
2(2.3 \%) \\
0 \\
5(5.8 \%) \\
1(1.1 \%) \\
5(5.8 \%) \\
17(20 \%) \\
0 \\
22(26 \%) \\
2(2.4 \%) \\
0 \\
5(5.9 \%) \\
10(12 \%) \\
7(8.2 \%) \\
2(2.3 \%) \\
1(1.2 \%)\end{array}$ & $\begin{array}{c}1(1.6 \%) \\
31(49 \%) \\
2(3.2 \%) \\
1(1.6 \%) \\
0 \\
0 \\
0 \\
3(4.8 \%) \\
0 \\
0 \\
1(1.6 \%) \\
0 \\
0 \\
15(24 \%) \\
5(7.9 \%) \\
4(6.3 \%) \\
0\end{array}$ \\
\hline $\begin{array}{l}\text { History of primary regimen failure, } \mathrm{n}(\%) \\
\text { Not treated } \\
\text { Discontinued for safety reason } \\
\text { Relapse } \\
\text { Non-response } \\
\text { Other }{ }^{*}\end{array}$ & $\begin{array}{l}77(90.6 \%) \\
3(3.5 \%) \\
1(1.2 \%) \\
2(2.3 \%) \\
2(2.4 \%)\end{array}$ & $\begin{array}{l}42(66.7 \%) \\
5(7.9 \%) \\
5(7.9 \%) \\
6(9.6 \%) \\
5(7.9 \%)\end{array}$ \\
\hline $\begin{array}{l}\text { Baseline, mean } \pm \mathrm{SD} \text { (min-max) } \\
\text { Albumin, g/dL } \\
\text { Hemoglobin, g/dL } \\
\text { Platelet count, G/L } \\
\text { Creatinine, } \mathrm{mg} / \mathrm{dL}\end{array}$ & $\begin{array}{c}4.0(0.4) ; 2.5-4.7 \\
12.8(2.2) ; 7.5-17.5 \\
195(66.1) ; 43.0-449 \\
1.9(1.2) ; 0.5-5.3\end{array}$ & $\begin{array}{l}3.9(6.8) ; 2.3-4.3 \\
11.4(1.9) ; 6.9-16.4 \\
173(57.8) ; 64-355 \\
\text { NA }\end{array}$ \\
\hline Time since transplantation (months), median (range) & $151(98) ; 3-350$ & NA \\
\hline $\begin{array}{l}\text { Baseline eGFR }\left(\mathrm{mL} / \mathrm{min} / 1,73 \mathrm{~m}^{2}\right), \mathrm{n}(\%) \\
\quad<30 \\
30-60 \\
>60\end{array}$ & $\begin{array}{c}\mathrm{n}=69 \\
21(30.4 \%) \\
20(29 \%) \\
28(40.6 \%)\end{array}$ & NA \\
\hline
\end{tabular}




\begin{tabular}{lcc} 
& & Ktx $\mathrm{n}=85$ \\
\cline { 2 - 3 } & $\mathrm{n}=69$ & $\mathrm{n}=63$ \\
\hline Immunosuppressant medication, $\mathrm{n}(\%)$ & $50(72.5 \%)$ & $\mathrm{NA}$ \\
Tacrolimus & $19(27.5 \%)$ \\
Cyclosporine & $54(78.3 \%)$ \\
Mycophenolate mofetil & $2(2.9 \%)$ \\
Sirolimus & $54(78.3 \%)$ & \\
Glucocorticoids &
\end{tabular}

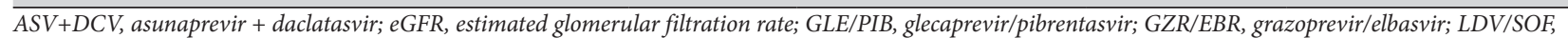
ledipasvir/sofosbuvir; $M E L D$, model for end-stage liver disease; OBV/PTV/r+/-DSV, ombitasvir/paritaprevir/ritonavir+/-dasabuvir; RBV, ribavirin

in treatment choice. The most common immunosuppressive regimen was a tri-medication with prednisone, tacrolimus and mycophenolate mofetil. At EOT, undetectable HCV RNA was noted in 84 patients $(99 \%)$. The only patient with a detectable viral load at the EOT was treatment naïve, with low-grade liver fibrosis (F1), infected with GT1b, who received 8 weeks of the sofosbuvir/ledipasvir regimen, but he finally achieved SVR12. Five of 85 patients were lost to follow up, but all available for final evaluation achieved SVR. Therefore, the SVR rate calculated according to ITT analysis was $94 \%$, whereas according to mITT it was $100 \%$ (Fig. 1).

No death or acute kidney rejection was observed. There was one treatment discontinuation after 7 weeks due to adverse effects, although finally this patient achieved SVR. The most common adverse events were anemia, fatigue, weakness, headaches, and itching (Table 2). In patients who had undergone $\mathrm{KTx}$ all the cases of anemia were related to ribavirin treatment.

One year after EOT, the kidney function, measured as a change in creatinine concentration, eGFR and proteinuria, was stable in most cases, with respective values of $64 \%, 57 \%$ and $87 \%$ (Table 3). However, the difference between baseline and EOT, was not statistically significant for any of these 3 measures.

The calcineurin inhibitor concentration changes were more significant for tacrolimus, which resulted from the antiviral regimen selection (Table 4). The dosage of tacrolimus was modified in $86 \%$ of patients during antiviral treatment and increased in more than half (54\%) after the EOT (Table 5).

Among 63 hemodialyzed patients, the majority were male $(60 \%)$ and the mean age was $51 \pm 13$ years (Table 1$)$. As in the post-KTx patients, the most common GT was $1 \mathrm{~b}(86 \%)$. In $64 \%$ patients, significant liver fibrosis $\geq \mathrm{F} 2$ was noted, including cirrhosis in $22 \%$. None of the patients presented liver decompensation or hepatocellular carcinoma. Forty-two patients $(67 \%)$ were treatment naïve, while the remainder had failed to achieve SVR despite interferon-based therapy. The most commonly selected antiviral regimen, administered to more than half of the patients (56\%), was OPrD. The treatment lasted for 8-24 weeks and 9 patients (14\%) received ribavirin, which was discontinued during the treatment. Two patients discontinued treatment because of adverse events. HCV RNA was undetectable at the EOT in all patients, including those
Table 2 Adverse events during antiviral treatment in patients after kidney transplantation and in hemodialysis patients

\begin{tabular}{|c|c|c|c|c|}
\hline Adverse event & $\mathrm{n}=85$ & $\%$ & $\mathrm{n}=63$ & $\%$ \\
\hline Death & 0 & 0 & 0 & 0 \\
\hline Acute rejection & 0 & 0 & NA & NA \\
\hline Treatment discontinuation & 1 & 1.1 & 2 & 3.1 \\
\hline Anemia & 23 & 27.0 & 20 & 31.7 \\
\hline Weakness & 22 & 25.8 & 7 & 11.1 \\
\hline Fatigue & 22 & 25.8 & 2 & 3.1 \\
\hline Headache & 4 & 4.7 & 2 & 3.1 \\
\hline Pruritus & 3 & 3.5 & 3 & 4.3 \\
\hline Giddiness & 1 & 1.1 & 1 & 1.5 \\
\hline Urosepsis Proteus mirabilis & 1 & 1.1 & 0 & 0 \\
\hline Vomiting & 1 & 1.1 & 1 & 1.5 \\
\hline Hypotension & 1 & 1.1 & 1 & 1.5 \\
\hline Nightmare & 1 & 1.1 & 0 & 0 \\
\hline Nausea & 1 & 1.1 & 1 & 1.5 \\
\hline Limb pain & 1 & 1.1 & 0 & 0 \\
\hline Swelling & 1 & 1.1 & 0 & 0 \\
\hline Cough & 1 & 1.1 & 1 & 1.5 \\
\hline Muscle weakness & 1 & 1.1 & 0 & 0 \\
\hline Malaise & 1 & 1.1 & 0 & 0 \\
\hline
\end{tabular}

NA, not available

who discontinued treatment. The SVR12 rate according to ITT was $97 \%$, whereas calculated according to mITT it was $100 \%$ (Fig. 1). There were no deaths during the treatment or follow-up period. The most common adverse events were anemia, weakness, fatigue, headache, and itching. Anemia was noted in all hemodialyzed patients who were administered ribavirin, and additionally in 11 patients without ribavirin in their antiviral regimen. The deepening anemia resulted from complications of the underlying disease and had no relation to the antiviral treatment.

None of the patients required blood transfusion, and all hemodialyzed patients were administered erythropoietin according to the procedures of renal replacement therapy. 


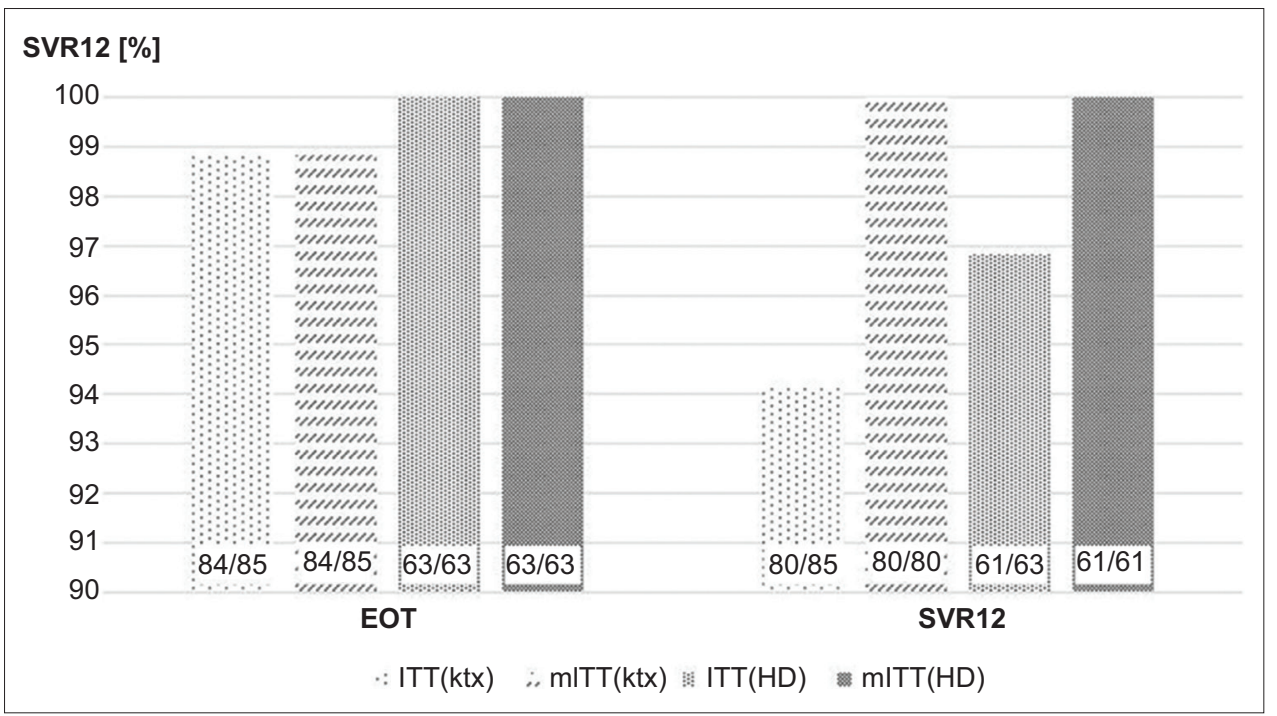

Figure 1 Virologic response at the end of treatment (EOT) and 12 weeks after treatment termination (SVR) in patients after kidney transplantation and in hemodialyzed patients

EOT, end of treatment; SVR, sustained virologic response; KTx, kidney transplantation; HD, hemodialysis; ITT, intention to treat; mITT, modified ITT

Table 3 Changes in the values of creatinine concentration, eGFR and proteinuria in patients after kidney transplantation one year after EOT (data for 69 patients)

\begin{tabular}{llcc} 
Parameter & & $\mathrm{n}$ & $\%$ \\
\hline Creatinine & decrease & 17 & 24.6 \\
concentration & stable & 44 & 63.8 \\
& increase & 8 & 11.6 \\
eGFR & decrease & 12 & 17.4 \\
& stable & 39 & 56.5 \\
Proteinuria & increase & 18 & 26.1 \\
& increase & 2 & 2.9 \\
& stable & 60 & 87 \\
\hline eGFR estimated glomerular filtration rate; EOT end of treatment &
\end{tabular}

Discontinuation of the treatment was due to itching or headache.

\section{Discussion}

According to the newest recommendations of the European Association for the Study of the Liver, non-hepatic solid organ transplant recipients, including kidney, heart, lung, pancreas or small bowel recipients, should be treated for their HCV infection before or after transplantation, and such patients require individual assessment [22].

Before KTx, patients on the waiting list can be treated according to the general recommendations, with no need for dose adjustments of HCV DAAs. In patients with endstage renal disease requiring hemodialysis, the fixed-dose
Table 4 Mean \pm SD concentration of tacrolimus and cyclosporin, at baseline, maximal during DAA treatment and one year after EOT in patients after kidney transplantation (data for 69 patients)

$\begin{array}{lcc}\text { Trough level }(\mathrm{ng} / \mathrm{mL}) & \text { Tacrolimus, } & \text { Cyclosporine, } \mathrm{n}=19 \\ \text { mean } \pm \text { SD; } \min -\max & \mathrm{n}=50 & \end{array}$

\begin{tabular}{lcc}
\hline Baseline & $5.8(1.3) ; 2.4-8.7$ & $130.1(85.8) ; 54.0-366.2$ \\
$\begin{array}{l}\text { Maximal during DAA } \\
\text { treatment }\end{array}$ & $7.6(2.7) ; 4.4-15.3$ & $145.2(127.1) ; 78.0-500.0$ \\
\hline $\begin{array}{l}\text { One year after EOT } \\
\text { DAA, direct-acting antivirals; EOT, end of treatment; SD, standard deviation }\end{array}$
\end{tabular}

Table 5 Modification of the calcineurin inhibitor dosage

\begin{tabular}{lcc}
\hline Calcineurin inhibitor & $\begin{array}{c}\text { Dose modification } \\
\mathrm{n}=69\end{array}$ & Comment \\
\hline Tacrolimus, $\mathrm{n}=50$ & $43(86.0 \%)$ & $\begin{array}{c}27(54.0 \%) \text { Dose } \\
\text { increase after the EOT }\end{array}$ \\
Cyclosporine, $\mathrm{n}=19$ & $7(36.8 \%)$ & $\begin{array}{c}1(5.3 \%) \text { Dose increase } \\
\text { after the EOT }\end{array}$ \\
\hline
\end{tabular}

EOT, end of treatment

combination of glecaprevir and pibrentasvir, the fixed-dose of grazoprevir and elbasvir or ombitasvir/paritaprevir/ritonavir +/- dasabuvir (for patients infected with GT1b only) are the preferred choices. In case of liver decompensation (ChildPugh B or C) and mild to moderate renal impairment (eGFR $\geq 30 \mathrm{~mL} / \mathrm{min} / 1.73 \mathrm{~m}^{2}$ ) the patient should be treated with a fixed dose combination of sofosbuvir and velpatasvir with ribavirin for 12 weeks or without ribavirin for 24 weeks in severe renal impairment $\left(\mathrm{eGFR}<30 \mathrm{~mL} / \mathrm{min} / 1.73 \mathrm{~m}^{2}\right)$.

After KTx, recipients should be treated with a fixed-dose combination of sofosbuvir and velpatasvir for 12 weeks, without the need for immunosuppressant drug dose adjustments, or 
a fixed-dose combination of glecaprevir and pibrentasvir for 12 weeks. However, the immunosuppressant drug levels need to be monitored and adjusted as needed during and after the EOT. The glecaprevir/pibrentasvir combination can be recommended in patients with mild, moderate or severe graft impairment, especially with eGFR $<30 \mathrm{~mL} / \mathrm{min} / 1.73 \mathrm{~m}^{2}$.

The multicenter project Epiter-2 was initiated in order to assess the effectiveness and safety of DAA treatment of chronic HCV infections in Poland [10]. The project selected patients with end-stage renal failure and those who had undergone KTx. The variety of antiviral treatment schemes was not always the result of the researchers' choice, but could also be the only available treatment option. The most common choice of antiviral regimen among hemodialyzed patients was ombitasvir/paritaprevir/ritonavir + dasabuvir +/- ribavirin, administered to 35 patients (55.5\%). All hemodialyzed patients showed an undetectable viral load at the end of the antiviral treatment. Similar results were reported by Lawitz et al [23]. SVR was achieved by $95 \%$ of patients infected with $\mathrm{HCV}$ GT 1 and 4, treated with ombitasvir/paritaprevir/ritonavir +dasabuvir +/- ribavirin, of whom $76 \%$ were hemodialyzed.

A very good safety profile and 99\% SVR rate were obtained in hemodialyzed patients treated with elbasvir/grazoprevir in the C-SURFER study, which was the second most common treatment schema administered to chronic dialysis patients in EpiTer-2 ( $n=20,31.7 \%)$ [24]. Among the hemodialyzed patients, it is worth highlighting the group of $22 \%$ with cirrhosis and 6 patients $(9.52 \%)$ with HCV GT4. These factors, as well as HCV GT 1a in 3 additional patients, could support the decision to add ribavirin to the treatment, as it is a well-known cause of severe hematologic complications in hemodialyzed patients [25]. Although none of these patients required packed red blood cell transfusion, in all cases physicians were forced to discontinue ribavirin, which did not affect the SVR. Despite contraindications, a full daily dose of sofosbuvir/ledipasvir was administered to 4 hemodialyzed patients. According to a meta-analysis by Li et al [26], based on data from 717 patients treated with a sofosbuvir regimen in advanced renal disease, $58 \%$ of whom were hemodialyzed, the SVR rate was $95 \%$. The authors suggested that sofosbuvir could be safely administered to patients in stages 4 and 5 of chronic kidney disease.

Although none of the hemodialyzed patients in our study received treatment with glecaprevir/pibrentasvir, it is worth noting that the regimen was $100 \%$ effective in 24 hemodialyzed patients and $97 \%$ effective in 101 patients with chronic kidney disease in stages 3b, 4 or 5 [27,28]. According to Gane et al [29], the $98 \%$ SVR rate was achievable in 85 hemodialyzed patients treated with glecaprevir/pibrentasvir. In all these studies the most frequent adverse effect was pruritus; another was anemia, which resolved after treatment termination [27].

The use of DAA after KTx is a practice based on a few clinical trials, which confirmed their effectiveness and safety, although these data are still based on small groups. It is not surprising that $60 \%$ of patients included in EpiTer- 2 after $\mathrm{KTx}$ received sofosbuvir, because it reduces the probability of interaction with calcineurin inhibitors. Regardless of the treatment's duration ( 12 vs. 24 weeks) and ribavirin use, almost all patients responded to treatment with a low rate of adverse events and no effect on the functioning of the transplanted kidney [30-33]. According to Colombo et al [31], treatment with sofosbuvir/ledipasvir in 114 patients infected with HCV GT 1 and 4 provided a 100\% SVR rate, and the most common adverse events were weakness, fatigue and headaches, similar to our study.

Patients with progressive graft failure can also be treated for $\mathrm{HCV}$, with a pangenotypic glecaprevir/pibrentasvir regimen. In the multicenter study MAGELLAN-2 half of the 20 patients who had undergone KTx had an initial eGFR $<60 \mathrm{~mL} / \mathrm{min} / 1.73 \mathrm{~m}^{2}$, and all of them reached SVR [34]. We included one treatment-naïve patient, with minimal liver fibrosis, who received glecaprevir/pibrentasvir 3 months after a second KTx and showed stable, albeit not satisfactory, kidney function (eGFR $25 \mathrm{~mL} / \mathrm{min} / 1.73 \mathrm{~m}^{2}$ ). Successful therapy was completed within 8 weeks without significant complications and with gradual improvement in kidney function following treatment termination. As our centers had no access to glecaprevir/pibrentasvir during the period of the study, 17 (20\%) transplanted patients from our study were administered grazoprevir/elbasvir with a very good effectiveness and safety profile. The same $100 \%$ efficacy and safety was achieved in the study of Eisenberger et al [35], which included 10 patients treated with grazoprevir/elbasvir. Despite the initial advanced kidney disease, with an average eGFR of $29 \mathrm{~mL} / \mathrm{min} / 1.73 \mathrm{~m}^{2}$, no serious adverse effects, episodes of rejection or progression of the transplanted organ failure were reported [35].

After KTx, patients treated with sofosbuvir and velpatasvir do not require any adjustment of the dosage of the calcineurin inhibitor. Antiviral treatment with glecaprevir and pibrentasvir in patients who are being administered tacrolimus increases 1.45-fold in TAC AUC (area under curve), which does not require any adjustment of tacrolimus dosage. However, monitoring of the concentration is necessary, along with any required dosage adjustments. In patients treated with cyclosporin in dosages higher than $100 \mathrm{mg}$ daily, due to even a 5-fold increase in glecaprevir AUC such treatment is not recommended [36].

Given the variety of antiviral treatment in the studied group it is worth mentioning the remaining DAA interactions with calcineurin inhibitors. Ritonavir, a strong CYP3A inhibitor, part of a complex treatment with paritaprevir/ ritonavir/ombitasvir + dasabuvir (PrOD), increases TAC AUC 57.1-fold. The suggested initial dosage for TAC in this case was $0.5 \mathrm{mg}$ every 7 days, along with the monitoring of tacrolimus concentration and further dosage adjustments. In the case of cyclosporin the CSA AUC increases 5.8-fold, and for this reason the CSA dosage was reduced to $1 / 5$. During the elbasvir/grazoprevir treatment, the TAC AUC increases 1.43-fold, and the tacrolimus dosage does not require any adjustments [37]. However, the elbasvir/grazoprevir treatment is not recommended for patients treated with cyclosporin. The need to modify the dosage of calcineurin inhibitors, most often an increase after the end of antiviral therapy, can be the result of the curing of the HCV infection and the improvement in liver function $[30,35,38]$.

According to Wong et al [39], treatment with DAA for HCV infection resulted in better 1 -year survivability of a kidney 
graft compared to previous years, when there was no available interferon-free therapy. Goetsch et al [40] followed 18 kidney recipients successfully treated with DAA for 5 years and demonstrated a lower risk of kidney damage episodes or death compared to patients with a chronic active HCV infection. Our oneyear long observation of transplanted kidney function did not allow us to formulate similar conclusions. Therefore, it is still not clear whether successful DAA treatment of HCV infection can really improve the function of the transplanted kidney and prolong the patient's survival. The major limitation of our study is its retrospective nature, typical for real-world experience studies and resulted in the loss of some clinical and laboratory data.

In conclusion, the presented data confirm the high effectiveness and safety of DAAs in patients with kidney failure, kidney transplant candidates and patients after kidney transplant regardless of primary diseases, immunosuppressive treatment and possible drug-drug interactions.

\section{Summary Box}

\section{What is already known:}

- Direct-acting antiviral (DAA) therapy provides an opportunity to eradicate the hepatitis C virus (HCV) among the most difficult groups of patients: those with decompensated cirrhosis, after transplantation or with advanced chronic kidney diseases

- DAA treatment guarantees a near $100 \%$ virologic response; is short, typically taking 8-12 weeks, based on ingestion of 1-day tablets; has few drug-drug interactions and side effects; and is mostly ribavirin-free, which increases the safety, regardless of liver fibrosis and previous treatment

- The eradication of the HCV virus in hemodialyzed patients decreases the total risk of comorbidity and mortality in patients treated with renal replacement therapy

\section{What the new findings are:}

- In a yearly observation of the studied kidney post-transplant group, a lowering of creatinine concentration, an increase in estimated glomerular filtration rate, and a decrease in proteinuria were observed in $24.6 \%, 26.1 \%$ and $10.1 \%$ respectively, which remained stable in $63.8 \%, 56.5 \%$ and $87 \%$ of patients, respectively

- The DAA antiviral treatment can have a positive effect on the survivability of the transplanted kidney

- In hemodialyzed patients with advanced liver fibrosis, HCV eradication could avoid the need for liver transplantation

\section{References}

1. World Health Organization. Hepatitis C. 2020. Available from: http://www.who.int/news-room/fact-sheets/detail/hepatitis-c [Accessed 21 December 2020].

2. Corouge M, Vallet-Pichard A, Pol S. HCV and the kidney. Liver Int 2016;36(Suppl 1):28-33.

3. Corson M, Moch A, Saab S. Hepatitis C virus treatment in patients with chronic kidney disease and in kidney transplant recipients. Gastroenterol Hepatol (N Y) 2018;14:280-285.

4. Domínguez-Gil B, Morales JM. Transplantation in the patient with hepatitis C. Transpl Int 2009;22:1117-1131.

5. Ko HM, Hernandez-Prera JC, Zhu H, et al. Morphologic features of extrahepatic manifestations of hepatitis $\mathrm{C}$ virus infection. Clin Dev Immunol 2012;2012:740138.

6. Burra P, Rodríguez-Castro KI, Marchini F, et al. Hepatitis C virus infection in end-stage renal disease and kidney transplantation. Transpl Int 2014;27:877-891.

7. Kidney Disease: Improving Global Outcomes (KDIGO) Hepatitis C Work Group. KDIGO 2018 Clinical Practice Guideline for the Prevention, Diagnosis, Evaluation, and Treatment of Hepatitis C in Chronic Kidney Disease. Kidney Int Suppl (2011) 2018;8:91-165.

8. Heo NY, Mannalithara A, Kim D, Udompap P, Tan JC, Kim WR. Long-term patient and graft survival of kidney transplant recipients with hepatitis $\mathrm{C}$ virus infection in the United States. Transplantation 2018;102:454-460.

9. Cacoub P, Desbois AC, Isnard-Bagnis C, Rocatello D, Ferri C. Hepatitis $C$ virus infection and chronic kidney disease: time for reappraisal. J Hepatol 2016;65:S82-S94.

10. Flisiak R, Zarębska-Michaluk D, Janczewska E, et al. Treatment of $\mathrm{HCV}$ infection in Poland at the beginning of the interferon-free era-the EpiTer-2 study. J Viral Hepat 2018;25:661-669.

11. Dörr G, Dell Bello A, Abravanel F, et al. Malignancies in hepatitis C virus-positive and -negative kidney transplant recipients: A casecontrolled study. Transpl Infect Dis 2017;19(4).

12. Chute DF, Chung RT, Sise ME. Direct-acting antiviral therapy for hepatitis $\mathrm{C}$ virus infection in the kidney transplant recipient. Kidney Int 2018;93:560-567.

13. Kiberd BA, Doucette K, Vinson AJ, Tennankore KK. Hepatitis C virus-infected kidney waitlist patients: treat now or treat later? $\mathrm{Am}$ J Transplant 2018;18:2443-2450.

14. Baid-Agrawal S, Pascual M, Moradpour D, Somasundaram R, Muche M. Hepatitis C virus infection and kidney transplantation in 2014: what's new? Am J Transplant 2014;14:2206-2220.

15. European Association for the Study of the Liver. EASL recommendations on treatment of hepatitis C 2018. J Hepatol 2018;69:461-511.

16. Jadoul M, Martin P. Should all dialysis patients with hepatitis $C$ be treated? If so, before or after kidney transplantation? Semin Dial 2017;30:395-397.

17. Goldberg DS, Abt PL, Blumberg EA, et al. Trial of transplantation of HCV-infected kidneys into uninfected recipients. $N$ Engl J Med 2017;376:2394-2395.

18. Goldberg DS, Abt PL, Reese PP; THINKER Trial Investigators. Transplanting HCV-infected kidneys into uninfected recipients. $N$ Engl J Med 2017;377:1105.

19. Flisiak R, Zarębska-Michaluk D, Jaroszewicz J, et al. Changes in patient profile, treatment effectiveness, and safety during 4 years of access to interferon-free therapy for hepatitis $\mathrm{C}$ virus infection. Pol Arch Intern Med 2020;130:163-172.

20. Halota W, Flisiak R, Juszczyk J, et al; Polish Group of Experts for HCV. Recommendations for the treatment of hepatitis C in 2017. Clin Exp Hepatol 2017;3:47-55.

21. Halota W, Flisiak R, Juszczyk J et al. Recommendations of the Polish Group of Experts for HCV for the treatment of hepatitis C 
in 2020. Clin Exp Hepatol 2020;6:163-169.

22. European Association for the Study of the Liver. EASL recommendations on treatment of hepatitis C: Final update of the series. J Hepatol 2020;73:1170-1218.

23. Lawitz E, Gane E, Cohen E, et al. Efficacy and safety of ombitasvir/ paritaprevir/ritonavir in patients with hepatitis $\mathrm{C}$ virus genotype 1 or 4 infection and advanced kidney disease. Kidney Int Rep 2019;4:257-266.

24. Roth D, Nelson DR, Bruchfeld A, et al. Grazoprevir plus elbasvir in treatment-naive and treatment-experienced patients with hepatitis $\mathrm{C}$ virus genotype 1 infection and stage 4-5 chronic kidney disease (the C-SURFER study): a combination phase 3 study. Lancet 2015;386:1537-1545.

25. Carrion AF, Fabrizi F, Martin P. Should ribavirin be used to treat hepatitis C in dialysis patients? Semin Dial 2011;24:272-274.

26. Li M, Chen J, Fang Z, Li Y, Lin Q. Sofosbuvir-based regimen is safe and effective for hepatitis $C$ infected patients with stage 4-5 chronic kidney disease: a systematic review and meta-analysis. Virol J 2019;16:34.

27. Morishita A, Ogawa C, Moriya A, et al. Clinical outcomes of hepatitis $\mathrm{C}$ virus elimination using glecaprevir and pibrentasvir in hemodialysis patients: A multicenter study. Hepatol Res 2020;50:557-564.

28. Lawitz E, Flisiak R, Abunimeh M, et al. Efficacy and safety of glecaprevir/pibrentasvir in renally impaired patients with chronic HCV infection. Liver Int 2020;40:1032-1041.

29. Gane E, Lawitz E, Pugatch D, et al. Glecaprevir and pibrentasvir in patients with HCV and severe renal impairment. $N$ Engl J Med 2017;377:1448-1455.

30. Eisenberger U, Guberina H, Willuweit K, et al. Successful treatment of chronic hepatitis $\mathrm{C}$ virus infection with sofosbuvir and ledipasvir in renal transplant recipients. Transplantation 2017;101:980-986.

31. Colombo M, Aghemo A, Liu H, et al. Treatment with ledipasvirsofosbuvir for 12 or 24 weeks in kidney transplant recipients with chronic hepatitis $\mathrm{C}$ virus genotype 1 or 4 infection: a randomized trial. Ann Intern Med 2017;166:109-117.

32. Kamar N, Marion O, Rostaing L, et al. Efficacy and safety of sofosbuvir-based antiviral therapy to treat hepatitis $\mathrm{C}$ virus infection after kidney transplantation. Am J Transplant 2016;16:1474-1479.

33. Morales AL, Liriano-Ward L, Tierney A, et al. Ledipasvir/ sofosbuvir is effective and well tolerated in postkidney transplant patients with chronic hepatitis C virus. Clin Transplant 2017;31(5).

34. Reau N, Kwo PY, Rhee S, et al. Glecaprevir/pibrentasvir treatment in liver or kidney transplant patients with hepatitis C virus infection. Hepatology 2018;68:1298-1307.

35. Eisenberger U, Friebus-Kardash J, Guberina H, et al. Treatment with grazoprevir/elbasvir for renal transplant recipients with chronic hepatitis $\mathrm{c}$ virus infection and impaired allograft function. Transplant Direct 2019;5:e419.

36. Maviret, INN-glecaprevir, pibrentasvir. Summary of product characteristics. Available from: https://www.ema.europa.eu/ en/documents/product-information/maviret-epar-productinformation_en.pdf [Accessed 5 January 2021]

37. Viekirax, INN- ombitasvir, paritaprevir, ritonavir. Summary of product characteristics. Available from: https://www.ema.europa. eu/en/documents/product-information/viekirax-epar-productinformation_en.pdf [Accessed 5 January 2021]

38. Reddy S, Sharma RK, Mehrotra S, et al. Efficacy and safety of sofosbuvir-based antiviral therapy to treat hepatitis $C$ virus infection after kidney transplantation. Clin Kidney J 2018;11:429-433.

39. Wong K, Cholankeril G, Ahmed A. Improved short-term survival in $\mathrm{HCV}$ seropositive kidney transplant recipients during the DAA era in the United States. AASLD 2018 Nov 9-13 SF Oral 224. Available from: https://www.natap.org/2018/AASLD/AASLD_164. htm [Accessed 5 January 2021]

40. Goetsch MR, Tamhane A, Overton ET, et al. Direct Acting Antivirals in Hepatitis C-Infected Kidney Transplant Recipients: Associations with Long-term Graft Failure and Patient Mortality. Pathog Immun 2020;5:275-290. 